\section{Commentary: Keep the head cool. Keep the spine cooler}

\author{
Mehrdad Ghoreishi, MD, ${ }^{\mathrm{a}}$ and Joseph Coselli, $\mathrm{MD}^{\mathrm{b}, \mathrm{c}, \mathrm{d}}$
}

Spinal cord deficit is an extremely rare event after total transverse aortic arch replacement with hypothermic circulatory arrest. ${ }^{1-4}$ Notably, there have been a handful of reports describing paraplegia or paraparesis after "extended" total aortic arch repair that also includes a portion of the descending thoracic aorta, such as during "long" elephant trunk or frozen elephant trunk repairs. Because of the recent general shift toward warmer temperatures during aortic arch repair, there is some concern regarding inadvertent harm to the spinal cord. The question is whether antegrade cerebral perfusion (ACP) itself is protective against paraplegia in long-interval moderate hypothermic circulatory arrest or if the surgeon should rely more on protection provided by hypothermia.

Kinoshita and colleagues ${ }^{7}$ investigated brain and spinal cord oxygen saturation levels using near-infrared spectroscopy (NIRS) at the forehead and along the mid-line of the back at the T3 and T10 level in 18 patients undergoing total transverse aortic arch replacement. The oxygen saturation levels declined immediately in all levels after initiation of circulatory arrest at a tympanic membrane temperature of less than $25^{\circ} \mathrm{C}$. The oxygen saturation levels increased in the forehead right after the initiation of ACP and remained partially elevated at upper thoracic level (T3), but continued to decline without recovery at the lower thoracic level

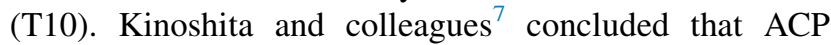
partially perfuses the upper thoracic spinal cord via

From the a Division of Cardiac Surgery, University of Maryland School of Medicine, Baltimore, Md; ${ }^{b}$ Division of Cardiothoracic Surgery, Michael E. DeBakey Department of Surgery, Baylor College of Medicine, Houston, Tex; ' Department of Cardiovascular Surgery, Texas Heart Institute, Houston, Tex; and ${ }^{\mathrm{d}} \mathrm{CHI}$ St Luke's Health-Baylor St Luke's Medical Center, Houston, Tex.

Disclosures: Dr Coselli consults for, receives royalties and a departmental educational grant from, and participates in clinical trials for Terumo Aortic; consults and participates in clinical trials for Medtronic, Inc, and WL Gore \& Associates, Edwards Lifesciences, and Abbott Laboratories; and serves as a co-investigator for CytoSorbents. Dr Coselli's work is partly supported by the co-investigator for CytoSorbents. Dr Coselli's work is partly supported by the Cullen Foundation. The other author has nothing to disclose with regard to commercial support.

Received for publication July 24, 2019; accepted for publication July 25, 2019; available ahead of print Aug 22, 2019

Address for reprints: Joseph Coselli, MD, One Baylor Plaza, BCM 390, Houston, TX 77030 (E-mail: jcoselli@bcm.edu).

J Thorac Cardiovasc Surg 2020;160:44-5

$0022-5223 / \$ 36.00$

Copyright (c) 2019 by The American Association for Thoracic Surgery

https://doi.org/10.1016/j.jtcvs.2019.07.080

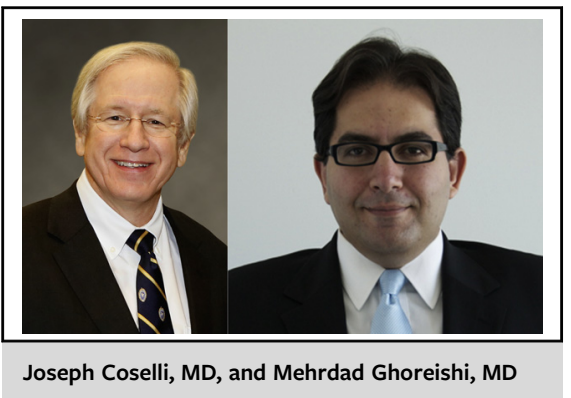

CENTRAL MESSAGE

Until we obtain an accurate modality to monitor spinal cord perfusion, extra caution should be taken in aortic arch replacement when warmer temperatures are used during hypothermic circulatory arrest.

collateral circulation from vertebral arteries through an anterior spinal artery, with no or minimal effect on lower thoracic cord perfusion during circulatory arrest. The authors state that cooling is more protective against spinal cord neurologic deficit than is ACP.

Perhaps the authors could have also highlighted the importance of restoring perfusion to the downstream aorta immediately after the distal anastomosis is completed to minimize the potential for distal ischemia-they did indicate oxygen saturation improved upon resuming lower body cardiopulmonary bypass, which may be readily provided by using a side perfusing branch of the main replacement graft. Most surgeons understand that both the circle of Willis and the feeding arteries of the spinal cord are highly variable and inherently complex, but few perform detailed preoperative imaging to identify anomalies; instead, blanket protections are undertaken to cover most scenarios, although the risk of postoperative spinal cord deficit remains a threat after complex aortic repair. ${ }^{8}$

Unfortunately, there is currently no direct way to measure spinal cord blood flow at the time of lower body circulatory arrest. Kinoshita and colleagues ${ }^{7}$ believe that oxygen saturation levels detected by NIRS along the paraspinal muscles are an indirect indicator of spinal cord blood flow-a phenomenon not yet clearly accepted. Moreover, the position of NIRS optodes is a debated question. Some prefer to place optodes directly above the vertebrae, ${ }^{9}$ and others position the optodes above the paravertebral muscles, 
called "indirect paraspinal collateral network monitoring." ${ }^{10}$ Regardless of the positioning of the optodes, available animal studies ${ }^{11,12}$ have shown promising correlations between NIRS data on regional oxygenation and spinal cord perfusion. Further clinical trials are deemed necessary to investigate if NIRS detected spinal oxygen saturation is an accurate modality for spinal cord blood flow.

In most studies, including the current one, the perfusion pressure with ACP is maintained at (or below) $50 \mathrm{~mm} \mathrm{Hg}$ to prevent any cerebral edema. However, one wonders whether a slightly higher ACP perfusion pressure and flow (closer to $60 \mathrm{~mm} \mathrm{Hg}$ ) or a lower degree of hypothermia $\left(<22^{\circ} \mathrm{C}\right)$ would have any impact on the NIRS-detected oxygen saturation of the spinal cord. Until we obtain an accurate modality to monitor spinal cord perfusion in real time (both intraoperatively and postoperatively), extra caution should be taken in total transverse aortic arch replacement when warmer temperatures during hypothermic circulatory arrest are used for long intervals.

\section{References}

1. Coselli JS, Green SY. Aortic arch repair today: open repair is best for most arch lesions. J Cardiovasc Surg (Torino). 2015;56:531-46.

2. Hanif H, Dubois L, Ouzounian M, Peterson MD, El-Hamamsy I, Dagenais F, et al. Aortic arch reconstructive surgery with conventional techniques vs frozen elephant trunk: a systematic review and meta-analysis. Can J Cardiol. 2018;34:262-73.
3. Settepani F, Cappai A, Basciu A, Barbone A, Tarelli G. Outcome of open total arch replacement in the modern era. J Vasc Surg. 2016;63:537-45.

4. Svensson LG. Protecting the brain and spinal cord in aortic arch surgery. Ann Cardiothorac Surg. 2018;7:345-50.

5. Kondoh H, Taniguchi K, Funatsu T, Toda K, Masai T, Takahashi T, et al. Total arch replacement with long elephant trunk anastomosed at the base of the innominate artery: a single-centre longitudinal experience. Eur J Cardiothorac Surg. 2012;42:840-8.

6. Shrestha M, Bachet J, Bavaria J, Carrel TP, De Paulis R, Di Bartolomeo R, et al. Current status and recommendations for use of the frozen elephant trunk technique: a position paper by the Vascular Domain of EACTS. Eur $J$ Cardiothorac Surg. 2015;47:759-69.

7. Kinoshita T, Yoshida H, Hachiro K, Suzuki T, Asai T. Spinal cord collateral flow during antegrade cerebral perfusion for aortic arch surgery. J Thorac Cardiovasc Surg. 2020;160:37-43.

8. Coselli JS, LeMaire SA, Preventza O, de la Cruz KI, Cooley DA, Price MD, et al. Outcomes of 3309 thoracoabdominal aortic aneurysm repairs. J Thorac Cardiovasc Surg. 2016;151:1323-37.

9. Boezeman RP, van Dongen EP, Morshuis WJ, Sonker U, Boezeman EH, Waanders FG, et al. Spinal near-infrared spectroscopy measurements during and after thoracoabdominal aortic aneurysm repair: a pilot study. Ann Thorac Surg. 2015;99:1267-74.

10. Etz CD, von Aspern K, Gudehus S, Luehr M, Girrbach FF, Ender J, et al. Nearinfrared spectroscopy monitoring of the collateral network prior to, during, and after thoracoabdominal aortic repair: a pilot study. Eur J Vasc Endovasc Surg. 2013;46:651-6.

11. LeMaire SA, Ochoa LN, Conklin LD, Widman RA, Clubb FJ Jr, Undar A, et al Transcutaneous near-infrared spectroscopy for detection of regional spinal ischemia during intercostal artery ligation: preliminary experimental results. $J$ Thorac Cardiovasc Surg. 2006;132:1150-5.

12. von Aspern K, Haunschild J, Ziemann M, Misfeld M, Mohr FW, Borger MA et al. Evaluation of collateral network near-infrared spectroscopy during and after segmental artery occlusion in a chronic large animal model. J Thorac Cardiovasc Surg. 2019;158:155-64.e5.

\section{Commentary: No cord left behind}

John Bozinovski, MD, MSc, and

Asvin M. Ganapathi, MD

Until recently, protection from end-organ injury during aortic arch surgery has focused on the brain. The primary means for organ protection was hypothermia, and because the organ most susceptible to ischemia is the brain, there

\footnotetext{
From the Division of Cardiac Surgery, The Ohio State University Wexner Medical Center, Columbus, Ohio.

Disclosures: Authors have nothing to disclose with regard to commercial support.

Received for publication July 26, 2019; accepted for publication July 29, 2019; available ahead of print Sept 5, 2019.

Address for reprints: John Bozinovski, MD, MSc, N816A Doan Hall, 410 W 10th

Ave, Columbus, OH 43210 (E-mail: jovan.bozinovski@osumc.edu).

J Thorac Cardiovasc Surg 2020;160:45-6

$0022-5223 / \$ 36.00$

Copyright (c) 2019 by The American Association for Thoracic Surgery

https://doi.org/10.1016/j.jtcvs.2019.07.119
}

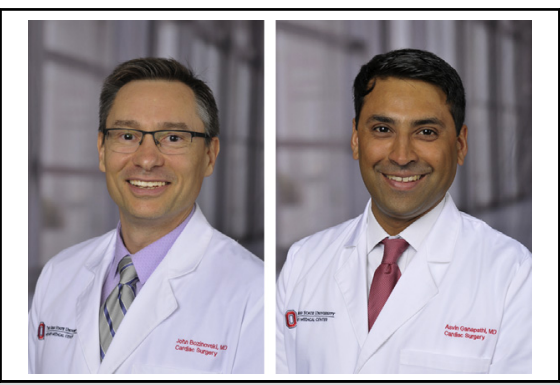

John Bozinovski, MD, MSc (left), and Asvin M Ganapathi, MD (right)

CENTRAL MESSAGE

The move to warmer tempera-

tures during aortic arch surgery

should not abandon consider-

ation of the risk to the spinal

cord. 